\title{
Case fatality rates after admission to hospital with stroke: linked database study
}

\author{
Stephen E Roberts, Michael J Goldacre
}

Population based mortality for stroke has declined in most Western countries during the past few decades. ${ }^{1}$ This is probably because of a decrease in both the incidence of and case fatality from stroke over this period..$^{2-4}$ Routine statistics generally do not provide long term trends in case fatality, and few studies have looked at differences in case fatality rates between hospitals. ${ }^{5}$ We used routine hospital data, which had been linked to mortality data in the former Oxford health region of England, to study case fatality rates after admission for stroke and to compare rates between different periods and different hospitals.

\section{Methods and results}

We calculated case fatality rates by dividing the number of deaths from all causes after admission by the number of admissions for stroke and multiplying by 100. We compared case fatality rates for deaths anywhere at 30, 90, and 365 days after admission and for deaths in the hospital admission for acute stroke. Following convention, we termed the latter "inhospital" deaths. We analysed only emergency admissions for which stroke was the principal diagnosis. We used ICD-9 (international classification of diseases, 9th revision) codes 431-434 and 436 (ICD-10 codes I61-I64). Data had been collected by the region from 10 acute hospitals for $1978-87$ and 12 for 1988-97 (with follow up during 1988 and 1998, respectively). Some hospital trusts had merged by 1998 .

During the 20 years of data collection, 34080 people were admitted to hospital with strokes; 18126 (53.2\%) were women. The mean age was 73.7 (SD 12.3) years.

Standardised case fatality rates for patients admitted for stroke, by hospital of admission during 1978-87 and 1988-97*

\begin{tabular}{|c|c|c|c|c|c|}
\hline \multirow[b]{3}{*}{ Hospital } & \multirow{3}{*}{$\begin{array}{c}\text { No of } \\
\text { admissions }\end{array}$} & \multicolumn{4}{|c|}{ Case fatalities $(95 \% \mathrm{Cl})$} \\
\hline & & \multirow{2}{*}{$\begin{array}{l}\text { In-hospital deaths } \\
<30 \text { days }\end{array}$} & \multicolumn{3}{|c|}{ Deaths anywhere } \\
\hline & & & $<30$ days & $<90$ days & $<365$ days \\
\hline \multicolumn{6}{|l|}{ 1978-87 } \\
\hline It & 2933 & 29.7 (27.6 to 31.8 ) & 32.5 (30.3 to 34.7 ) & 40.9 (38.4 to 43.5$)$ & 50.3 (47.5 to 53.1$)$ \\
\hline II & 936 & 33.7 (30.0 to 37.5$)$ & 37.5 (33.5 to 41.5$)$ & 47.3 (42.8 to 51.8 ) & 57.0 (52.0 to 61.9$)$ \\
\hline III & 1138 & 37.1 (33.2 to 41.0$)$ & 41.2 (37.0 to 45.3$)$ & 50.4 (45.8 to 55.0$)$ & 58.6 (53.6 to 63.5 ) \\
\hline IV & 1422 & 41.7 (38.1 to 45.2 ) & 47.3 (43.5 to 51.1 ) & 54.6 (50.5 to 58.7 ) & 63.1 (58.7 to 67.5$)$ \\
\hline V & 566 & 44.8 (37.6 to 52.0$)$ & 47.2 (39.8 to 54.5 ) & 58.3 (50.0 to 66.6 ) & 64.7 (56.1 to 73.3 ) \\
\hline VI & 1249 & 35.2 (31.9 to 38.5$)$ & 36.5 (33.1 to 39.8 ) & 43.6 (39.9 to 47.3 ) & 53.3 (49.2 to 57.3 ) \\
\hline VII & 1187 & 43.4 (39.3 to 47.5$)$ & 47.1 (42.9 to 51.3 ) & 54.5 (49.9 to 59.1 ) & 61.7 (56.9 to 66.5$)$ \\
\hline VIIII & 2104 & 34.5 (32.0 to 37.0$)$ & 36.8 (34.1 to 39.4 ) & 44.6 (41.7 to 47.5$)$ & 55.9 (52.7 to 59.1$)$ \\
\hline IX & 853 & 43.4 (38.2 to 48.7 ) & 45.2 (39.9 to 50.5$)$ & 52.1 (46.4 to 57.7 ) & 60.4 (54.3 to 66.5$)$ \\
\hline$\underline{x}$ & 467 & 41.9 (35.7 to 48.1$)$ & 44.8 (38.4 to 51.2 ) & 52.4 (45.4 to 59.4 ) & 59.3 (51.9 to 66.7$)$ \\
\hline Subtotal IIIIX & 9922 & 38.6 (37.4 to 39.9 ) & 41.8 (40.5 to 43.1 ) & 49.7 (48.3 to 51.1$)$ & 58.8 (57.3 to 60.4 ) \\
\hline Totalf & 12855 & 36.6 (35.5 to 37.7 ) & 39.7 (38.5 to 40.8 ) & 47.7 (46.4 to 48.9$)$ & 56.9 (55.5 to 58.2$)$ \\
\hline Unadjusted case fatality rate & & 35.4 (34.5 to 36.2 ) & 38.4 (37.5 to 39.2 ) & 45.9 (45.1 to 46.8 ) & 54.6 (53.7 to 55.5 ) \\
\hline$\chi^{2}, d f=162 \S$ & & 278.1 & 305.6 & 307.8 & 281.2 \\
\hline \multicolumn{6}{|l|}{ 1988-97 } \\
\hline It & 4289 & 25.7 (24.2 to 27.3 ) & 28.6 (27.0 to 30.3 ) & 35.5 (33.7 to 37.3$)$ & 44.8 (42.8 to 46.8$)$ \\
\hline II & 1233 & 35.4 (32.1 to 38.7 ) & 36.4 (33.0 to 39.7 ) & 43.0 (39.3 to 46.7$)$ & 51.9 (47.8 to 55.9$)$ \\
\hline III & 1718 & 23.1 (20.7 to 25.4$)$ & 36.3 (33.4 to 39.2 ) & $42.9(39.7$ to 46.1$)$ & 52.4 (48.9 to 55.9$)$ \\
\hline IV & 2624 & 29.9 (27.8 to 32.0$)$ & 33.1 (30.8 to 35.3 ) & 41.5 (39.0 to 44.0$)$ & 50.8 (48.1 to 53.6$)$ \\
\hline $\mathrm{V}$ and $\mathrm{VI}$ & 2522 & 30.4 (28.3 to 32.6$)$ & 33.0 (30.8 to 35.3 ) & 39.6 (37.2 to 42.1$)$ & 45.9 (43.3 to 48.6$)$ \\
\hline VII and VIII & 3657 & 32.2 (30.4 to 34.1 ) & 34.3 (32.4 to 36.2 ) & 42.0 (39.9 to 44.1$)$ & 50.0 (47.7 to 52.2$)$ \\
\hline$I X$ and $X$ & 2475 & 30.1 (27.9 to 32.2 ) & 34.0 (31.7 to 36.3 ) & 43.0 (40.4 to 45.5$)$ & 50.8 (48.0 to 53.6$)$ \\
\hline $\mathrm{XI}$ & 1357 & 28.7 (25.9 to 31.4$)$ & 30.9 (28.0 to 33.9 ) & 37.6 (34.3 to 40.8$)$ & 46.3 (42.7 to 49.9$)$ \\
\hline XII & 1350 & 32.8 (29.7 to 35.9 ) & 34.7 (31.5 to 37.9 ) & 43.6 (40.0 to 47.2$)$ & 52.8 (48.8 to 56.7 ) \\
\hline Subtotal II-XII & 16936 & 30.5 (29.6 to 31.3 ) & 34.0 (33.1 to 34.9 ) & 41.6 (40.6 to 42.6 ) & 49.9 (48.8 to 51.0$)$ \\
\hline Totalł & 21225 & 29.5 (28.8 to 30.2 ) & 32.9 (32.1 to 33.7 ) & 40.3 (39.5 to 41.2$)$ & 48.9 (47.9 to 49.8$)$ \\
\hline Unadjusted case fatality rate & & 29.7 (29.1 to 30.3 ) & 33.1 (32.5 to 33.8 ) & 40.7 (40.0 to 41.3 ) & 49.3 (48.6 to 49.9 ) \\
\hline$\chi^{2}, \mathrm{df}=144 \S$ & & 282.9 & 250.9 & 266.7 & 263.8 \\
\hline
\end{tabular}

${ }^{*}$ Standardised for age group and sex by the direct method, with all patients admitted for stroke in the former Oxford region in 1978-1997 as the standard for making comparisons over time and between hospitals.

†Differences between the teaching hospital (hospital I) and other hospitals combined at 30 days were $9.3 \%$ (95\% confidence interval $7.3 \%$ to $11.3 \%, P<0.001$ ) in

$1978-87$ and $5.4 \%(3.9 \%$ to $6.9 \%, P<0.001)$ in 1988-97. Differences between the teaching hospital and the other hospitals combined at $30-365$ days (that is,

excluding deaths in the first 30 days) were $-0.8 \%(-2.4$ to $0.8, P=0.31)$ in $1978-87$ and $-0.3 \%(-1.5$ to $0.9, P=0.63)$ in $1988-97$.

łBetween $1978-87$ and $1988-97$, the total case fatality rates at 30 days decreased by $6.8 \%(5.7 \%$ to $7.9 \%, P<0.001)$ and for deaths from $30-365$ days after the acute event decreased by $1.2 \%(0.4 \%$ to $2.0 \%, P<0.01)$.

§obtained through logistic regression analysis. Provides an overall test of the variation in case fatality rates between all individual hospitals: comparisons between hospitals in all eight sets of case fatality rates were highly significant $(\mathrm{P}<0.001)$. Corresponding $\chi^{2}$ statistics that compared only the non-teaching hospitals were 187.1, 199.2, 206.9, and 180.4 for the four successive periods after admission for 1978-87 $\left(\mathrm{df}_{144}\right)$ and 209.3, 166.8, 178.2, and 202.4 for 1988-97 $\left(\mathrm{df}_{126}\right)$; all were significant $(P<0.01$ in seven cases and $P<0.05$ in one case). Chi-square statistics for variation in case fatality rates comparing all hospitals from 30 days to 365 days (that is, excluding deaths in the first 30 days) were non-significant in 1978-87 (183.2, $\left.\mathrm{df}_{162}, \mathrm{P}=0.24\right)$ and 1988-97 (161.8, $\left.\mathrm{df}_{144}, \mathrm{P}=0.29\right)$.

Unit of Health-Care Epidemiology, Department of Public Health, Institute of Health Sciences, University of Oxford, Oxford OX3 7LF

Stephen E Roberts statistician

Michael J Goldacre director

Correspondence to: M J Goldacre michael.goldacre@ dphpc.ox.ac.uk

BMJ 2003;326:193-4 on bmj.com 
In 1978-87, case fatality rates for all hospitals combined were $39.7 \%$ at 30 days and $56.9 \%$ at one year (table). In 1988-97, the corresponding figures were $32.9 \%$ and $48.9 \%$. The table shows that case fatality rates were lower for the region's teaching hospital (I) than for all other hospitals combined. Significant differences were also seen between individual nonteaching hospitals. Variation between the teaching hospital and individual non-teaching hospitals reduced over time.

Differences in case fatality rates during the first 30 days accounted for the differences between hospitals and most of the difference over time (table ). For 198897 , the low case fatality rate for in-hospital deaths in hospital III within 30 days, calculated without data linked to death certificates, was as high as that in other hospitals when linked data were used. Otherwise, case fatality rates for in-hospital deaths were good predictors of hospitals' relative rankings when rates were calculated with data linked to death certificates (Spearman's rank correlation coefficients between in-hospital deaths and deaths anywhere at 30, 90, and 365 days were $0.83,0.86$, and 0.88 in $1987-98$ and 0.93 , 0.81 , and 0.71 in 1988-97).

Age and sex standardised case fatality rates at 30 days in 1978-87 and 1988-97 were 33.2 and 24.7 in people $<75$ years and 27.5 and 19.8 in those $<65$. Differences between hospitals for case fatality rates in patients $<75$ and $<65$ years were similar to those found for patients of all ages, although with diminishing statistical power not all comparisons reached significance (see tables A-C on bmj.com).

\section{Comment}

Case fatality rates after hospital admission for stroke were high: about half of all patients died within one year. Differences in case fatality rates over time, and between hospitals, might be explained by differences in the case mix and particularly by differences in the severity of stroke and the extent to which patients were managed at home rather than in hospital. For these reasons, differences are hard to interpret. If the differences can be attributed to standards of care, rather than case mix, their impact is greatest in the acute phase of care: the reductions over time, and the differences between hospitals, were predominantly seen in fatality rates within 30 days of admission.

We thank Ruth M Ripley for advice about statistical methods. Contributors: SR designed the study, analysed the data, and wrote the manuscript. MG designed the study and wrote the manuscript. MG and SR are guarantors for the paper.

Funding: SR receives funding from the Department of Health as part of its funding for the National Centre for Health Outcomes Development (the views expressed in this paper are those of the authors and not necessarily those of the Department of Health). The Unit of Health-Care Epidemiology is funded by the South East Regional Office of the NHS Executive.

Competing interests: None declared.

1 Charlton J, Murphy M, Khaw K, Ebrahim S, Davey Smith G. Cardiovascular diseases. In: Charlton J, Murphy M, eds. The health of adult Britain 1841-1944:volume 2. London: Stationery Office, 1997:60-81.

2 Bonita R, Broad JB, Beaglehole R. Changes in stroke incidence and casefatality in Auckland, New Zealand, 1981-91. Lancet 1993;342:1470-3.

3 Why has stroke mortality declined? Lancet 1983;i:1195-6.

4 Malmgren R, Warlow C, Bamford J, Sandercock P. Geographical and Malmgren R, Warlow C, Bamford J, Sandercock P. Geog
secular trends in stroke incidence. Lancet 1987;ii:1196-200.

5 Wolfe CD, Tilling K, Beech R, Rudd AG. Variations in case fatality and dependency from stroke in western and central Europe. The European BIOMED study of stroke care group. Stroke 1999;30:350-6.

(Accepted 24 June 2002)

\section{Career choices of United Kingdom medical graduates of 1999 and 2000: questionnaire surveys}

Trevor W Lambert, Michael J Goldacre, Gill Turner

UK Medical

Careers Research

Group, Unit of

Health-Care

Epidemiology,

University of

Oxford, Oxford

OX3 7LF

Trevor W Lambert statistician

Michael J Goldacre director

Gill Turner

research officer

Correspondence to:

T Lambert

trevor.lambert@

dphpc.ox.ac.uk

BMJ 2003;326:194-5
The career choices of doctors at the end of their preregistration year have been studied for doctors who qualified in the United Kingdom in 1974, 1977, 1980, $1983,1988,1993$ and $1996 .{ }^{1-4}$ We report here on the graduates of 1999 and 2000.

\section{Participants, methods, and results}

The survey population comprised all graduates from all medical schools in the United Kingdom in 1999 and 2000. We used graduation lists from each medical school to compile our database. The doctors were sent a questionnaire towards the end of their preregistration year; non-respondents were sent a maximum of four reminders. As in earlier surveys, ${ }^{1-4}$ graduates were asked to state up to three choices of long term career in order of preference and to indicate whether they intended to practise medicine in the United Kingdom for the foreseeable future. We grouped career choices specified by the respondents into 14 mainstream specialties based on those defined in the Todd report. ${ }^{5}$ We used $\chi^{2}$ statistics and adjusted residuals to compare cohorts. ${ }^{1}$

The two cohorts consisted of 8661 graduates, of whom 23 were unregistered at the time of the surveys. Of the 8638 who were registered, 20 declined to participate, two were known to be dead, and 122 were untraceable. The remaining 8494 comprised 4104 men and 4390 women, of whom 5702 (67.1\%) replied. The proportion of women graduates who responded was significantly higher than that of the men $(73.7 \% v$ $60.1 \%, \chi^{2}=175.9, \mathrm{df}=1, \mathrm{P}<0.001$ ).

The table shows the junior doctors' first choices of long term mainstream specialty and compares them with the respondents of 1996 (table). We found no difference in the distribution of first choices between the graduates of 1999 and $2000\left(\chi^{2}=14.1, \mathrm{df}=13, \mathrm{P}>0.05\right)$ and a significant difference between those of 1999 and 2000 combined and $1996\left(\chi^{2}=83.5, \mathrm{df}=13, \mathrm{P}<0.001\right)$. Choices for general practice increased, whereas choices for hospital medical specialties, surgical 